\title{
Redissolution of caesium and plutonium from Irish Sea sediments: A comparison between different modelling approaches
}

\author{
M. losjpe ${ }^{1}$ and R. Periáñez ${ }^{2}$ \\ ${ }^{1}$ NRPA, Grini naringspark 13, 1332 Osteras, Norway, e-mail: mikhail.iosjpe@nrpa.no \\ ${ }^{2}$ Dpto Física Aplicada 1, EUITA, University of Seville, Ctra Utrera km 1, 41013 Sevilla, Spain \\ e-mail: rperianez@us.es
}

\begin{abstract}
Two models with different conceptual and numerical approaches have been used to simulate the dispersion of radionuclides released from Sellafield nuclear fuel reprocessing plant. The first is a long-term box-model for simulating dispersion from Sellafield to the Arctic environment in which water fluxes between boxes are obtained from basic oceanographic information. Water-sediment radionuclide exchanges are described through sedimentation and remobilisation processes on the basis of equilibrium distribution coefficients. The second model is a 3D high-resolution model that explicitly solves tidal mixing and suspended sediment transport in the Irish Sea. Exchanges of radionuclides between the liquid and solid phases are now described in terms of kinetic rates. Thus, this model has a general applicability and can be used in situations out from equilibrium. Both models have been used to simulate the dispersion of $\mathrm{Cs}$ and $\mathrm{Pu}$ in the Irish Sea. Results from the two models are comparable, being differences in the results smaller than should be expected from the very different modelling approaches.
\end{abstract}

\section{INTRODUCTION}

Box models can be used for simulating radiological consequences of radioactivity releases in the marine environment with spatial and temporal scales of several thousand kilometres and millenniums, respectively. This approach covers whole processes: dispersion of radionuclides in oceanic space, transfer of radioactivity between seawater and sediments, uptake of radionuclides by biota and, finally, dose calculations for man, which are important for radiological assessment. Therefore, box modelling has been recommended by the European Commission for radiological assessment. On the other hand, high-resolution models have been developed to simulate the dispersion of radionuclides at smaller spatial and temporal scales. These models (either in a 2D or 3D form) calculate currents by means of a hydrodynamic sub-model, which may be run either on-line or off-line. Computed currents are then used to solve the advection/diffusion dispersion equation. Interactions of radionuclides between the liquid and solid phases (suspended matter and bed sediments) may be described by means of kinetic transfer coefficients. Thus, these models can be used for situations out from equilibrium.

A box model describing long term transport in the North Atlantic and Arctic environments has been described in (1). This model is an improved version of that previously presented by Nielsen et al (2) since includes non-instantaneous mixing in the oceanic space. A high resolution 3D model for simulating radionuclide dispersion in the Irish Sea is described in (3) and (4). The objective of this work consists of comparing the outputs from both models when simulating the dispersion of radionuclides released from Sellafield nuclear fuel reprocessing plant. This allows testing the description of mixing and interactions with sediments carried out from very different conceptual and numerical approaches. If comparable results are obtained, this would give confidence to both modelling approaches. 
Materials (models used) and method for the comparisons are described in the following section. Next, results are presented and discussed.

\section{MATERIALS AND METHODS}

\subsection{Long-term box model for the North Atlantic and Arctic Oceans}

In these models the oceanic space is divided into a number of boxes that exchange radionuclides according to effective transfer rates deduced from oceanographic information. First order differential equations are used to describe these processes. External sources of radionuclides and radioactive decay can be added to the equations. Furthermore, it is assumed that, at any time, the activity in the water column is partitioned between the dissolved phase and the suspended sediment. The fraction of the activity remaining in solution is described by the partition coefficient, that depends on the suspended sediment concentration and on the radionuclide equilibrium distribution coefficient, $\mathrm{k}_{\mathrm{d}}$. Radionuclides associated with suspended sediments are transferred to underlying boxes when particles settle out, process described by a mass sedimentation rate. The model also includes the processes of diffusion of radioactivity through pore water, resuspension, mixing due to bioturbation and the burial of activity in the deep sediment.

The classic box modelling approach described in (2) was modified by Iosjpe et al (1) to avoid the assumption of instantaneous mixing of radionuclides into each model box, that leads, in practical calculations, to instantaneous mixing in the whole oceanic space. This feature of traditional box modelling is not liable to describe correctly the water motion of large oceanic systems. Thus, times of availability have been defined for each box in the model. These are defined as the first time when a given box is opened to accept radionuclides from the others. The mathematical description of the availability times can be seen in detail in Iosjpe et al (1).

The vertical structure of the model allows for the description of the water column through surface, mid-depth and deep waters. The volume of the water layers in each box has been calculated using detailed bathymetry in geographical information system.

\subsection{Irish Sea three dimensional dispersion model}

The Irish Sea model solves simultaneously (on-line) the hydrodynamic equations, the suspended matter equation and the equations for the dispersion of radionuclides. The model is full 3D, using normalized $\sigma$-coordinates in the vertical and a flow dependent eddy viscosity formulation. The suspended matter equation includes advection/diffusion of particles, settling, flocculation effects and deposition and erosion of the sediments. It is considered that radionuclides can be present in three phases: dissolved, suspended matter particles and bottom sediments. Exchanges of radionuclides between the phases are described in terms of kinetic transfer coefficients, and radionuclides in water and suspended matter will also be transported by advection and diffusion processes. The model has been applied to simulate the dispersion of $\mathrm{Cs}$ and $\mathrm{Pu}$, thus redox reactions have also been included since plutonium can exist in sea water in different oxidation states, with different affinities to be fixed to the solid phases (and thus different kinetic coefficients). Redox reactions are described by means of reduction and oxidation velocities. A two-step kinetic model consisting of two consecutive reversible reactions has been used to describe the interactions of dissolved radionuclides with the solid phases. The first reaction describes an interaction between dissolved radionuclides and some non-specific sites on particle surface. The second and slower reaction represents a reversible sorption to more specific sites. More details about the model can be found in references (3) and (4). 
The hydrodynamic model is forced by observed tides along open boundaries, thus tidal mixing is explicitly solved. Ten $\sigma$ layers are used in the vertical, horizontal resolution is $5 \mathrm{~km}$ and computational time step is $60 \mathrm{~s}$. As a consequence, long-term simulations cannot be carried out with this model. A maximum of a few years of dispersion can be simulated in reasonable computational times.

\subsection{Comparing both models}

It is clear that both models cover very different spatial and temporal scales. The box model may be used to carry out simulations over oceanic scales and over temporal scales of the order of thousand of years. On the other hand, the 3D model covers a relatively small coastal area (some $200 \times 125 \mathrm{~km}^{2}$ ) and much shorter temporal scales (maximum of a few years). Thus, if models are to be compared, it must be carefully checked that the same "question" is "asked" to both models.

In the box model the Irish Sea is divided into 7 boxes, each of them containing many grid cells of the 3D model. Results from both models have been compared for the Cumbrian Waters box, in the eastern Irish Sea. Results from the 3D model are obtained by averaging the spatial activity concentration over an area corresponding to that of the actual Cumbrian Waters box in the box model. Results from both models, obtained in such a way, are extracted at given times after starting the simulation.

Radionuclides used for comparisons are ${ }^{137} \mathrm{Cs}$ and ${ }^{239,240} \mathrm{Pu}$. Simulations correspond to $1 \mathrm{TBq}$ instantaneous discharge into the water column from Sellafield reprocessing plant and, on the other hand, $1 \mathrm{TBq}$ of each radionuclide initially distributed over the sediments of the Cumbrian Waters box. Computations extend over a temporal scale of 2 years.

\section{RESULTS AND DISCUSSION}

As an example, some results from the box model are presented in figure 1, where comparisons between model predictions and measurements are shown. Model results include releases from Sellafield, La Hague and fallout over the Irish Sea. The solid line corresponds to calculations while circles show the average value of measurements. Error bars, where shown, indicate the maximum and minimum values of the experimental data. More details on model results may be seen in (1).
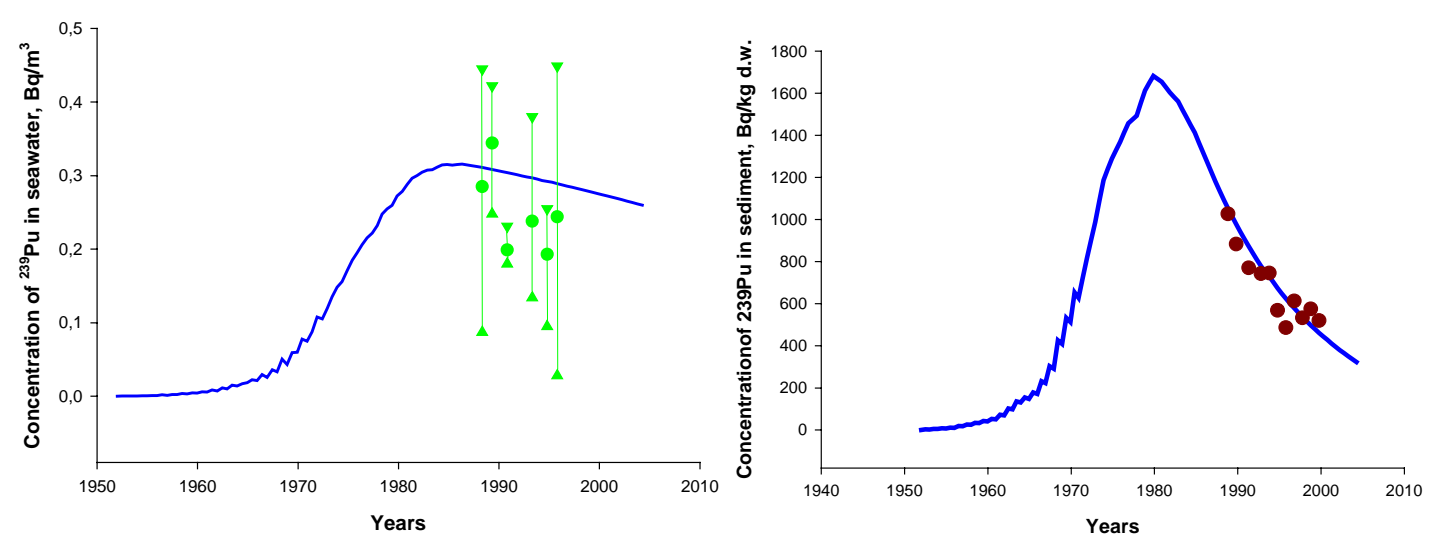

Figure 1. Model results and measurements for ${ }^{239} \mathrm{Pu}$ in surface water of the western Irish Sea (left) and in sediments of the Cumbrian Waters box (right). 
The 3D dispersion model was tested simulating the dispersion of Sellafield releases and comparing computed distributions of $\mathrm{Pu}$ in water, suspended matter and sediments with observations. The computed distribution of Pu between oxidized and reduced forms in the three phases has also been compared with observations, as well as $k_{d}$ distribution coefficients for oxidized, reduced and total Pu. Model results are, in general, in good agreement with observations $(3,4)$.

Two examples of the kinds of results that may be obtained from the 3D model are presented in figures 2 and 3.
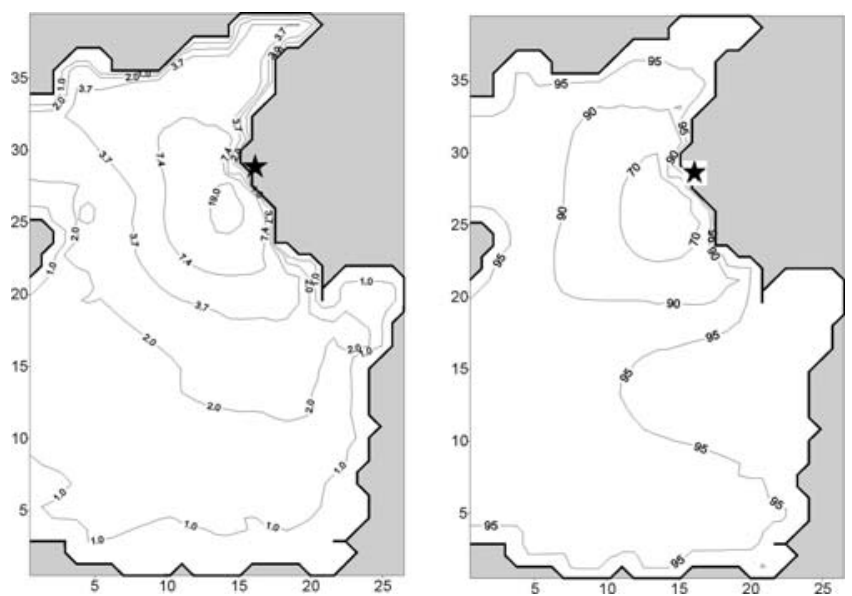

Figure 2. Computed distribution of plutonium in surface waters $\left(\mathrm{Bq} / \mathrm{m}^{3}\right)$ for year 1974 (left) and computed percentage of oxidized plutonium (right) in such waters.
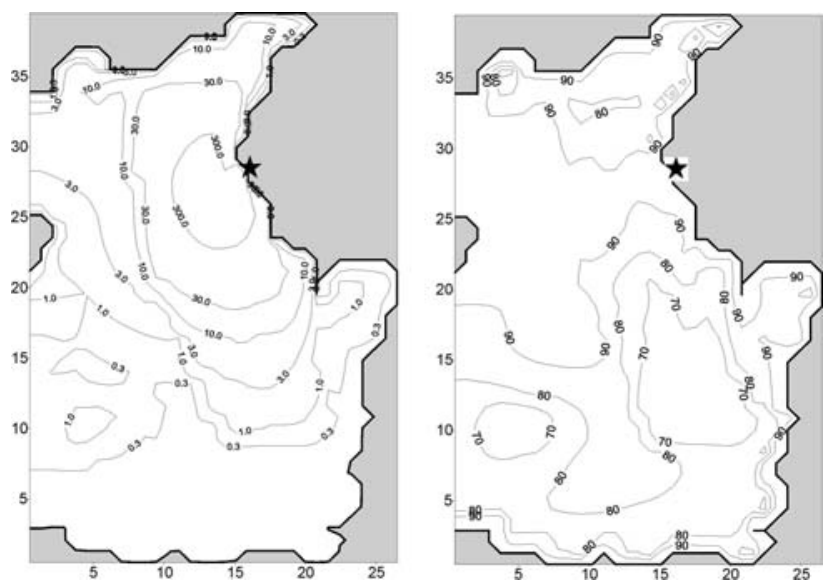

Figure 3. Computed distribution of plutonium in bed sediments $\left(\mathrm{kBq} / \mathrm{m}^{2}\right)$ for year 1977 (left) and computed fraction of reduced plutonium in the sediment (right).

Results of the comparisons between the box model and the 3D model for the instantaneous release numerical experiment can be seen in table 1 . Computed concentrations of plutonium and cesium in the bed sediment and water of the Cumbrian Waters box several times after the instantaneous release from Sellafield are shown. Water and sediments over both model domains are assumed to be not contaminated at $\mathrm{t}=0$. Thus, the sediments are contaminated after the instantaneous release. Next, they are slowly cleaned by redissolution of radionuclides to the water column, which is cleaned faster due 
to transport processes. As a consequence, there is a slow reduction in radionuclide concentration in the sediment phase that can be appreciated in table 1 . Thus, this numerical experiment allows the comparison of model performances for both the processes of sorption and release of radionuclides by the sediment simultaneously.

Table 1 shows that, in spite of the very different approaches and description of water-sediment interaction processes used in both models, differences in the simulation are not more than a factor 3 , which is encouraging. The only exceptions are Cs in water during the first year, when differences reach one order of magnitude and in sediment during all the simulation (differences reach a factor 5).

Table 1. Comparison of the simulation results between the 3D and the box models for instantaneous releases of Cs and Pu from Sellafield plant. Concentrations in sediments and water of the Cumbrian Waters box for both radionuclides are shown.

\begin{tabular}{|c|c|c|c|c|c|c|c|c|}
\hline \multirow{2}{*}{$\begin{array}{c}\text { Time } \\
\text { (years) }\end{array}$} & \multicolumn{2}{|c|}{$\begin{array}{c}{ }^{137} \mathrm{Cs} \text { in sediment } \\
(\mathrm{Bq} / \mathrm{kg})\end{array}$} & \multicolumn{2}{c|}{$\begin{array}{c}{ }^{239,240} \mathrm{Pu} \text { in } \\
\text { sediment }(\mathrm{Bq} / \mathrm{kg})\end{array}$} & ${ }^{137} \mathrm{Cs}$ in water $\left(\mathrm{Bq} / \mathrm{m}^{3}\right)$ & \multicolumn{2}{c|}{$\begin{array}{c}{ }^{239,240} \mathrm{Pu} \text { in } \\
\text { water }\left(\mathrm{Bq} / \mathrm{m}^{3}\right)\end{array}$} \\
\cline { 2 - 9 } & 3D & box & $3 \mathrm{D}$ & box & $3 \mathrm{D}$ & box & $3 \mathrm{D}$ & box \\
\hline 0.5 & 0.42 & 1.6 & 2.5 & 7.1 & 0.042 & 0.44 & $6.2 \mathrm{e}-3$ & $8.6 \mathrm{e}-3$ \\
\hline 1.0 & 0.36 & 1.6 & 2.5 & 6.8 & 0.034 & 0.16 & $4.0 \mathrm{e}-3$ & $6.7 \mathrm{e}-3$ \\
\hline 1.5 & 0.30 & 1.5 & 2.5 & 6.6 & 0.028 & 0.036 & $3.5 \mathrm{e}-3$ & $6.4 \mathrm{e}-3$ \\
\hline 2.0 & 0.26 & 1.4 & 2.5 & 6.4 & 0.024 & 0.014 & $3.2 \mathrm{e}-3$ & $6.2 \mathrm{e}-3$ \\
\hline
\end{tabular}

Table 2. Comparison of the simulation results between the 3D and the box models when 1 TBq of Cs and Pu are initially distributed over the bed sediment in the Cumbrian Waters box. Concentrations in sediments and water of the Cumbrian Waters box for both radionuclides are shown.

\begin{tabular}{|c|c|c|c|c|c|c|c|c|}
\hline \multirow{2}{*}{$\begin{array}{l}\text { Time } \\
\text { (years) }\end{array}$} & \multicolumn{2}{|c|}{$\begin{array}{c}{ }^{137} \mathrm{Cs} \text { in sediment } \\
(\mathrm{Bq} / \mathrm{kg})\end{array}$} & \multicolumn{2}{|c|}{$\begin{array}{c}{ }^{239,240} \mathrm{Pu} \text { in } \\
\text { sediment }(\mathrm{Bq} / \mathrm{kg})\end{array}$} & \multicolumn{2}{|c|}{${ }^{137} \mathrm{Cs}$ in water $\left(\mathrm{Bq} / \mathrm{m}^{3}\right)$} & \multicolumn{2}{|c|}{$\begin{array}{l}{ }^{239,240} \mathrm{Pu} \text { in } \\
\text { water }\left(\mathrm{Bq} / \mathrm{m}^{3}\right)\end{array}$} \\
\hline & $3 \mathrm{D}$ & box & $3 \mathrm{D}$ & box & $3 \mathrm{D}$ & box & $3 \mathrm{D}$ & box \\
\hline 0.5 & 1.6 & 0.74 & 2.9 & 7.9 & 0.092 & 0.031 & $5.3 e-3$ & 7.6e-3 \\
\hline 1.0 & 1.4 & 0.65 & 2.9 & 6.8 & 0.074 & 0.044 & $4.4 \mathrm{e}-3$ & $7.4 \mathrm{e}-3$ \\
\hline 1.5 & 1.2 & 0.63 & 2.9 & 6.0 & 0.065 & 0.050 & $4.2 \mathrm{e}-3$ & 7.1e-3 \\
\hline 2.0 & 0.98 & 0.57 & 2.9 & 5.1 & 0.053 & 0.055 & $3.8 \mathrm{e}-3$ & $6.9 \mathrm{e}-3$ \\
\hline
\end{tabular}

Results for the numerical experiment consisting of considering $1 \mathrm{TBq}$ of each radionuclide over the sediments of the Cumbrian Waters box at $\mathrm{t}=0$ are shown in table 2 . Water is assumed to be clean over the model domains at $t=0$, as well as sediments except in the mentioned area. Initially (first 10 days approximately, thus not apparent in table 2), there is an increase in water concentrations due to redissolution. Next they decrease as the redissloution process slows down and radionuclides in the water column are transported away from the area. Again, differences between both models for both phases and radionuclides remain below a factor 3 . Both models give a similar redissolution rate from the sediment in the case of Cs. However, Pu redissolution is much slower with the 3D model than with the box model (with this model Pu redissolution rate is similar to that of $\mathrm{Cs}$ ). This is probably due to the inclusion in the 3D model of Pu speciation between oxidized and reduced forms: reduced $\mathrm{Pu}$ is more particle reactive than the mixing of oxidation states that is usually considered in Pu dispersion models $(3,4)$. This mixing is characterised by an average $\mathrm{k}_{\mathrm{d}}$ between reduced and oxidized forms. Nevertheless, activity levels given by both models, as commented above, are rather similar.

Differences between the outputs of the models may be due, at least partially, to uncertainties in $\mathrm{k}_{\mathrm{d}}$ values, because this version of calculations by the box model does not include $\mathrm{k}_{\mathrm{d}}$ site-specific information for this sea region. Nevertheless, a general conclusion of this work is that very different modelling approaches can lead to comparable results if they are extracted in the correct way. 


\section{Acknowledgement}

Work supported by the EU Remotrans Project ( $5^{\text {th }}$ Framework Programme, contract FIGE-CT-2000-00085).

\section{References}

[1] M. Iosjpe, J. Brown, P. Strand. Journal of Environmental Radioactivity 60 (2002), 91-103.

[2] S.P. Nielsen, M. Iosjpe, P. Strand. The Science of the Total Environment 202 (1997), 135-146.

[3] R. Periañez. Journal of Environmental Radioactivity 62 (2002), 263-276.

[4] R. Periáñez. Journal of Marine Systems 38 (2003), 259-275. 